\title{
Valores de referência do lipidograma de bovinos da raça holandesa, criados no Estado de São Paulo
}

Fabio Celidonio POGLIANI ${ }^{1}$ Eduardo BIRGEL JUNIOR ${ }^{1}$

\section{Correspondência para:}

Eduardo Harry Birgel Junior

Av. Profo Dr. Orlando Marques de Paiva 87, Cidade Universitária Armando Salles de Oliveira CEP 05508-900, São Paulo - SP, e-mail:ehbirgel@usp.br

Recebido para publicação: 18/01/2007 Aprovado para publicação: 07/08/2007

1 - Centro de Pesquisa e Diagnóstico de Enfermidades de Ruminantes do Departamento de Clínica Médica da Faculdade de Medicina Veterinária e Zootecnia da Universidade de São Paulo, São Paulo-SP

\section{Resumo}

Com o intuito de estabelecer os valores de referência do lipidograma de bovinos, da raça Holandesa, criados no Estado de São Paulo foram examinadas amostras de soro e plasma sangüíneo de 413 bovinos clinicamente sadios. Baseado nos intervalos de confiança, recomendase a adoção dos valores de referência: colesterol - entre 86,5 e 120,8 $\mathrm{mg} / \mathrm{dL}$ para bezerros com até 3 meses; entre 46,3 e 79,7 mg/dL para bezerros com 3 a 12 meses; entre 86,4 e 105,0 mg/dL para novilhas com 12 a 24 meses e entre 116,0 e 147,9 mg/dL para vacas com mais de 24 meses de idade; triglicérides - entre 16,3 e 34,8 mg/dL para vacas com até 48 meses e entre 14,9 e 24,0 mg/dL para vacas com mais de 48 meses de idade; AGNE - entre 91,3 e 294,0 $\mu \mathrm{M} / \mathrm{L}$ independente da idade; $\beta$-HBO - entre 1,1 e 2,1 mg/dL para bezerros com até 3 meses e entre 3,37 e 6,2 mg/dL para animais com mais de 3 meses de idade; glicose - entre 75,1 e 88,3 mg/dL para bezerros com até 3 meses; entre 64,0 e 76,1 mg/dL para animais com 3 a 24 meses; entre: 60,6 e 67,2 $\mathrm{mg} / \mathrm{dL}$ para vacas com mais de 24 meses. Para machos adultos recomenda-se a adoção de valores de referência diferenciados para: colesterol - entre 73,9 e 90,2 mg/dL; B-HBO - entre 3,1 e 3,6 mg/dL e glicose - entre 71,9 e $76,5 \mathrm{mg} / \mathrm{dL}$. Os valores de referência apresentados não devem ser utilizados para vacas que estejam no último mês de gestação e nos primeiros 45 dias de lactação, recomendase para este período valores de referência específicos para animais no periparto.

\section{Introdução}

A importância da patologia clínica veterinária como meio semiológico, auxiliando os veterinários a estabelecerem diagnósticos, firmarem prognósticos e acompanharem os tratamentos das inúmeras enfermidades que atingem os animais domésticos é reconhecida e consagrada mundialmente. Entretanto, para que estes objetivos pudessem ser alcançados e utilizados na plenitude, tornou-se fundamental o conhecimento dos valores de referência para os parâmetros hematológicos e bioquímicos dos animais sadios, bem como dos fatores causadores de suas variações.

Entre esses fatores, um que merece destaque é a significativa influência dos fatores ambientais, havendo uma concordância, entre os pesquisadores que animais criados sob diferentes condições ambientais, climáticas e de manejo podem apresentar evidentes variações dos elementos constituintes sangüíneos. Assim sendo, os valores obtidos para os animais criados em uma região não podem ser considerados, sem uma adequada avaliação, como padrão de referência, fora desta região.

A literatura brasileira compulsada sobre os valores de referência do lipidograma de bovinos pode ser considerada escassa, sendo encontradas as seguintes pesquisas sobre o assunto, discriminadas na tabela 1 . À exceção da pesquisa de $\operatorname{Costa}^{1}$, na qual o referido autor procurou avaliar a influência 
Tabela 1 - Valores de referência do lipidograma de bovinos criados no Brasil. São Paulo, 2006

\begin{tabular}{cccccc}
\hline Autor (ano) & $\begin{array}{c}\text { Colesterol } \\
(\mathbf{m g} / \mathbf{d L})\end{array}$ & $\begin{array}{c}\text { Triglicérides } \\
(\mathbf{m g} / \mathbf{d L})\end{array}$ & $\begin{array}{c}\text { AGNE } \\
(\boldsymbol{\mu M} / \mathbf{L})\end{array}$ & $\begin{array}{c}\boldsymbol{\beta} \text {-HBO } \\
(\mathbf{m g} / \mathbf{d L})\end{array}$ & $\begin{array}{c}\text { Glicose } \\
(\mathbf{m g} / \mathbf{d L})\end{array}$ \\
\hline Vogel et al. $^{3}$ & - & - & - & - & $62,2 \pm 16,1$ \\
Costa $^{\mathbf{1}}$ & 98,2 a 165,3 & 12,0 a 16,1 & 145,0 a 353,0 & - & - \\
Mancio $^{4}$ & 118,5 & - & - & - & - \\
Oliveira $^{5}$ & 94,0 a 108,0 & - & - & - & - \\
Souza $^{37}$ & - & - & - & - & $67,7 \pm 1,3$ \\
Santos $^{6}$ & - & - & 243,0 & 5,209 & 58,7 \\
Borges $^{8}$ & $85,9 \pm 11,9$ & - & - & - & - \\
Sucupira $^{9}$ & - & - & 150,9 a 258,0 & 1,8 a 3,4 & 61,6 a 77,4 \\
${\text { Rennó } \text { Neto }^{\mathbf{1 0}}}$ & 131,1 a 149,0 & 11,7 a 17,4 & 131,9 a 164,6 & - & 52,8 a 58,8 \\
Maruta $^{11}$ & - & - & 108,0 a 124,5 & 4,7 a 5,9 & 70,2 a 77,3 \\
Souza $^{2}$ & 62,7 a 180,2 & 10,6 a 22,2 & 286,0 a 720,7 & 4,8 a 5,8 & 53,2 a 58,8 \\
\hline
\end{tabular}

da gestação e do puerpério sobre valores do colesterol e triglicérides e da pesquisa de Souza $^{2}$, na qual o referido autor procurou estabelecer os valores de referência dos constituintes do lipidograma para a fase puerperal e pós-puerperal, as demais pesquisas $3,4,5,6,7,8,9,10,11$ não tinham como intuito estabelecer valores de referência ou de avaliar fatores fisiológicos que pudessem interferir nos valores de normalidade do lipidograma ou somente avaliaram os teores de glicose.

A existência de poucas informações na literatura brasileira relativa ao metabolismo lipídico e, principalmente, a ausência, no Brasil, de pesquisas adequadamente planejadas para avaliar a influência de fatores indutores da variação dos seus valores como a influência dos fatores etários, sexuais e da gestação em bovinos estimularam a elaboração da presente pesquisa que cujo objetivo foi o de estabelecer os valores de referência do lipidograma de bovinos da raça Holandesa, criados no Estado de São Paulo.

\section{Material e Método}

Nesta pesquisa foram colhidas 413 amostras de soro e plasma sangüíneo de bovinos da raça Holandesa, criados em nove propriedades produtoras de leite dos tipos A e B, localizadas nos seguintes municípios paulistas: Caçapava, Paranapanema,
Itapetininga, Paraibuna, Santa Rita do Passa Quatro, Analândia, Descalvado e Pirassununga.

Em sete das nove propriedades utilizadas, as vacas lactantes eram mantidas em sistema semi-intensivo de criação, em pastos formados por capim Brachiaria decunbens, Brachiaria brizantha, Cynodon spp (Coast cross ou Tifton), recebendo forragem e concentrado de acordo com as necessidades de mantença e produção, sendo utilizado como volumoso a cana-de-açúcar com uréia ou silagem de milho ou de capim Napier e suplementação com a adição de concentrado comercial, caroço de algodão ou cevada. Nas duas propriedades restantes as vacas lactantes eram mantidas em sistema intensivo de criação, confinando-se os animais em galpões de estabulação livre e utilizando-se como volumoso a silagem de milho e feno de coast-cross, sendo esta dieta complementada pelo fornecimento de farelo de soja, farelo e/ou caroço de algodão, polpa cítrica e cevada. Todos os animais tinham acesso à sal mineral. Nas nove propriedades utilizadas de bovinos da raça Holandesa adotava-se o sistema de ordenha mecânica, sendo que os animais eram, de acordo com a sua produção de leite, ordenhados duas vezes ao dia com intervalos de 10 e 14 horas ou três vezes ao dia com intervalos de 8 horas. A produção leiteira 
média por vaca desses rebanhos, em 305 dias de lactação, variou entre 5000 e 8000 litros de leite.

Considerando-se a influência dos fatores etários, sexuais e da gestação, as amostras utilizadas para a determinação dos valores de referência do lipidograma foram distribuídas em grupos experimentais. Para a avaliação da influência dos fatores etários foram colhidas 273 amostras de soro e plasma distribuídas em 7 subgrupos experimentais: G1 - 20 bezerras com até 3 meses; G2 - 20 bezerras entre 3 e 6 meses; G3 - 20 bezerras entre 6 e 12 meses; G4 40 novilhas entre 12 e 24 meses; G5 - 73 vacas entre 24 e 48 meses; G6 - 55 vacas entre 48 e 72 meses; G7 - 45 vacas com mais de 72 meses de idade. Para avaliar a influência dos fatores sexuais foram colhidas amostras de soro e plasma de 30 machos adultos e 30 fêmeas adultas e para avaliar a influência da gestação e do puerpério foram colhidas 80 amostras de soro e plasma sangüíneos divididos em 5 subgrupos experimentais: G1 - 16 fêmeas não prenhes; G2 - 18 fêmeas com até 3 meses de gestação; G3 -15 fêmeas com 3 a 6 meses de gestação; G4 - 15 fêmeas com 6 a 9 meses de gestação; G5 - 16 fêmeas com até 30 dias de puerpério.

As amostras de sangue foram colhidas através da punção da veia jugular externa, utilizando-se o Sistema Vacutainer ${ }^{\circledR}$. As amostras para avaliação do colesterol, triglicérides, ácidos graxos não esterificados (AGNE) e B-Hidroxibutirato ( $B-\mathrm{HBO}$ ) foram colhidas em tubos de vidro siliconizados sem anti-coagulantes e mantidas em temperatura ambiente para facilitar a retração do coágulo. As amostras para a determinação dos teores plasmáticos de glicose foram colhidas em tubos de vidro siliconizados contendo fluoreto de sódio e mantidas refrigeradas durante o transporte. No laboratório as amostras foram centrifugadas com força real de centrifugação igual a $1000 \mathrm{~g}$, durante 15 minutos, para a ocorrência da sinérese do coágulo ou sedimentação dos elementos figurados do sangue, sendo, a seguir, o soro e o plasma sangüíneos separados por aspiração, e conservados em freezer a menos $20^{\circ} \mathrm{C}$ até a realização das provas.

A determinação dos teores séricos do lipidograma foi quantificada por metodologia enzimática colorimétrica, em Analisador Bioquímico modelo Liasys AMS - Itália. Os teores de AGNE foram determinados utilizando-se kit comercial da Randox ${ }^{\circledR}$ (FA 115), sendo a reação baseada em Elphick ${ }^{12}$. Os teores de colesterol foram determinados utilizando-se kit comercial da Biosystems ${ }^{\circledR}\left(\mathrm{N}^{\circ}\right.$ 11505), sendo a reação baseada em Allain et al. ${ }^{13}$. Os teores de triglicérides foram determinados utilizandose kit comercial da Biosystems ${ }^{\circledR}\left(\mathrm{N}^{\circ}\right.$ 11528), sendo a reação baseada em Fossati e Prencipe $^{14}$. Os teores de $\mathrm{B}-\mathrm{HBO}$ foram determinados utilizando-se kit comercial Randox ${ }^{\circledR}$ (FA 1007), sendo a reação baseada em Williamson et al. ${ }^{15}$. Para a determinação dos teores de glicose foi utilizado o método descrito por Barham e Trinder ${ }^{16}$, utilizandose kit comercial da marca Diasys ${ }^{\circledR}\left(\mathrm{N}^{\circ}\right.$ 10.250.021).

Os testes estatísticos, comparando as médias obtidas nos vários grupos experimentais e a determinação da média aritmética, o desvio-padrão, e a amplitude de variação dos resultados obtidos foram calculados através dos programas Microsoft Excel XP ${ }^{\circledR}$, SPSS 11.0 for Windows ${ }^{\circledR} \mathrm{e}$ Minitab 14.0 for Windows ${ }^{\circledR}$. Inicialmente aplicou-se o teste de Anderson-Darling e de Levene para testar se as variáveis estudadas seguiam uma Distribuição Normal e se a homocedasticidade (variâncias iguais) era satisfeita, sendo, nesses casos, utilizado a análise de variância, ANOVA, para testar a igualdade de médias. Para as variáveis em que a normalidade e homocedasticidade foram rejeitadas transformaram-se os dados em logaritmo neperiano, $\log _{\mathrm{e}}$, sendo as variáveis novamente submetidas ao teste de Anderson-Darling e de Levene. Sendo satisfeita a normalidade e/ou homocedasticidade, utilizou-se a análise de variância, ANOVA, para testar igualdade de médias. Nos casos em que a normalidade foi verificada, mas as variâncias não foram 
consideradas iguais, as médias foram comparadas por meio do teste de Brown e Forsythe ${ }^{17}$. Nas situações em que a igualdade de médias foi rejeitada, as médias foram comparadas duas a duas segundo o método de Bonferroni ou agrupadas segundo o método descrito de Calinski e Corsten ${ }^{18} \mathrm{e}$ Neter et al. ${ }^{19}$. Intervalos de confiança para os valores médios das variáveis foram construídos controlando-se o coeficiente de confiança global em 95\%.

\section{Resultados e Discussão}

Conforme pode ser visualizado na tabela 2, em decorrência à amamentação, nos primeiros três meses de vida, o lipidograma dos bezerros apresentaram algumas particularidades, pois os valores de colesterol e de glicose foram maiores, enquanto os de $B-H B O$ foram menores do que os observados nos bezerros desmamados com idade entre 3 e 6 meses. Após a desmama, o lipidograma continuou a sofrer influência da idade, pois com o início da puberdade, após os 12 meses de idade, os teores de colesterol aumentaram gradativamente atingindo valor máximo entre 24 e 48 meses, sendo que a partir desta idade o colesterol deixou de sofrer influência dos fatores etários. Na tabela 2 são apresentados, ainda, os intervalos de confiança encontrados nos grupos estudados para avaliação da influência dos fatores etários no lipidograma. Kappel et al. ${ }^{20}$ já haviam ressaltado que a idade é importante fator na avaliação dos valores de colesterol no sangue.

Respeitando-se essas faixas etárias e considerando-se os intervalos de confiança obtidos para esta variável, recomenda-se a adoção dos seguintes valores de referência para os teores de colesterol: entre 86,5 e $120,8 \mathrm{mg} / \mathrm{dL}$ para bezerros lactentes com até 3 meses de idade; entre 46,3 e 79,7 mg/ dL para bezerros desmamados com 3 a 12 meses de idade; entre 86,4 e $105,0 \mathrm{mg} / \mathrm{dL}$ para novilhas com 12 a 24 meses de idade; entre 116,0 e $147,9 \mathrm{mg} / \mathrm{dL}$ para vacas adultas com mais de 24 meses de idade.

Ao compararem-se os valores de referência obtidos nesta pesquisa com aqueles referidos na literatura compulsada verificouse que eles estão em concordância com os referidos por Oliveira ${ }^{5}$, Borges et al. ${ }^{8}$, Roussel et al. ${ }^{21}$ e Talavera et al. ${ }^{22}$, para novilhas, por Mancio $^{4}$, Rennó Neto ${ }^{10}$, Kappel et al. ${ }^{20}$,

Tabela 2 - Valores de referência do lipidograma (media \pm desvio-padrão e intervalo de confiança) de bovinos da raça Holandesa, criados no Estado de São Paulo, distribuídos segundo a influência dos fatores etários. São Paulo, 2006

\begin{tabular}{|c|c|c|c|c|c|c|}
\hline \multirow{2}{*}{$\begin{array}{l}\text { Idade dos } \\
\text { animais } \\
\text { (em meses) }\end{array}$} & \multirow{2}{*}{$\begin{array}{c}\begin{array}{c}\text { Número } \\
\text { de }\end{array} \\
\text { Amostras } \\
\end{array}$} & \multicolumn{5}{|c|}{ Constituinte do Lipidograma } \\
\hline & & $\begin{array}{c}\text { Colesterol } \\
(\mathrm{mg} / \mathrm{dL})\end{array}$ & $\begin{array}{l}\text { Triglicérides } \\
\text { (mg/dL) }\end{array}$ & $\begin{array}{c}\text { AGNE } \\
(\mu \mathrm{M} / \mathrm{L})\end{array}$ & $\begin{array}{l}\text { B-HBO } \\
\text { (mg/dL) }\end{array}$ & $\begin{array}{l}\text { Glicose } \\
\text { (mg/dL) }\end{array}$ \\
\hline$\leq 3$ & 20 & $\begin{array}{c}103,64 \pm 36,69 \\
(86,47-120,81)^{2}\end{array}$ & $\begin{array}{c}25,58 \pm 19,81 \\
(16,31-34,85)^{2}\end{array}$ & $\begin{array}{c}233,54 \pm 129,27 \\
(173,04-294,04)^{a}\end{array}$ & $\begin{array}{c}1,64 \pm 1,07 \\
(1,14-2,14)^{a}\end{array}$ & $\begin{array}{l}81,70 \pm 14,02 \\
(75,13-88,26)^{\mathrm{a}}\end{array}$ \\
\hline $3 \dashv 6$ & 20 & $\begin{array}{c}63,03 \pm 35,69 \\
(46,32-79,73)^{b}\end{array}$ & $\begin{array}{c}27,93 \pm 9,76 \\
(23,36-34,50)^{2}\end{array}$ & $\begin{array}{l}139,23 \pm 102,42 \\
(91,29-87,16)^{b}\end{array}$ & $\begin{array}{c}4,72 \pm 1,96 \\
(3,80-5,64)^{b}\end{array}$ & $\begin{array}{r}71,20 \pm 10,39 \\
(66,33-76,06)^{b}\end{array}$ \\
\hline $6 \dashv 12$ & 20 & $\begin{array}{c}58,11 \pm 20,64 \\
(48,44-67,76)^{b}\end{array}$ & $\begin{array}{c}23,62 \pm 9,30 \\
(19,26-27,97)^{2}\end{array}$ & $\begin{array}{c}150,48 \pm 99,01 \\
(104,13-196,81)^{b}\end{array}$ & $\begin{array}{c}4,05 \pm 1,11 \\
(3,53-4,57)^{b}\end{array}$ & $\begin{array}{c}68,25 \pm 9,03 \\
(64,02-72,47)^{b}\end{array}$ \\
\hline $12 \dashv 24$ & 40 & $\begin{array}{c}95,74 \pm 29,05 \\
(86,44-105,02)^{\mathrm{a}}\end{array}$ & $\begin{array}{c}31,32 \pm 15,82 \\
(26,26-36,37)^{2}\end{array}$ & $\begin{array}{c}210,53 \pm 146,08 \\
(163,81-257,25)^{c}\end{array}$ & $\begin{array}{c}3,79 \pm 1,3 \\
(3,37-4,20)^{b}\end{array}$ & $\begin{array}{r}69,77 \pm 11,66 \\
(66,04-73,50)^{b}\end{array}$ \\
\hline $24 \dashv 48$ & 73 & $\begin{array}{c}127,74 \pm 50,32 \\
(115,99-139,47)^{\mathrm{c}}\end{array}$ & $\begin{array}{c}24,49 \pm 17,02 \\
(20,51-28,45)^{2}\end{array}$ & $\begin{array}{c}238,57 \pm 165,05 \\
(200,05-277,07)^{\mathrm{c}}\end{array}$ & $\begin{array}{c}4,53 \pm 2,21 \\
(4,01-5,04)^{\mathrm{b}}\end{array}$ & $\begin{array}{c}65,75 \pm 6,13 \\
(64,32-67,18)^{c}\end{array}$ \\
\hline $48 \dashv 72$ & 55 & $\begin{array}{c}132,70 \pm 56,16 \\
(117,52-47,88)^{c}\end{array}$ & $\begin{array}{c}19,46 \pm 16,79 \\
(14,91-23,99)^{b}\end{array}$ & $\begin{array}{c}207,9 \pm 189,24 \\
(156,74-59,06)^{\mathrm{c}}\end{array}$ & $\begin{array}{c}5,52 \pm 2,4 \\
(4,86-6,16)^{b}\end{array}$ & $\begin{array}{c}62,70 \pm 6,67 \\
(60,90-64,51)^{c}\end{array}$ \\
\hline$>72$ & 45 & $\begin{array}{c}123,77 \pm 64,02 \\
(104,54-143,01)^{c}\end{array}$ & $\begin{array}{c}19,02 \pm 11,1 \\
(15,68-22,35)^{b}\end{array}$ & $\begin{array}{c}162,49 \pm 132,72 \\
(130,47-211,12)^{d}\end{array}$ & $\begin{array}{c}4,86 \pm 1,97 \\
(4,26-5,45)^{b}\end{array}$ & $\begin{array}{c}62,33 \pm 5,73 \\
(60,61-64,05)^{c}\end{array}$ \\
\hline
\end{tabular}

a,b,c,d: letras iguais na mesma coluna denotam ausência de diferença estatística significante $(\mathrm{p} \leq 0,05)$ - Método de Calinski e Corsten (colesterol, triglicérides, B-HBO e glicose) e Teste ANOVA (AGNE).

( ) : intervalo de confiança, intervalo no qual estão compreendidos $95 \%$ dos valores da população 
Arave et al. ${ }^{23}$, Roussel et al..$^{24}$, Grummer e Carrol ${ }^{25}$, para vacas adultas e estão em discordância com os resultados apresentados por Roussel et al..$^{24}$, Sinha et al. ${ }^{26} \mathrm{e} \mathrm{Williams}^{27}$ por serem maiores do que os valores encontrados nesta pesquisa.

Ao analisar os valores de referência propostos por Kweon et al. ${ }^{28}$, Smith ${ }^{29}$ e Kaneko et al. ${ }^{30}$, verificou-se que esses autores não especificaram a idade dos animais, tornando-os imprecisos e de pouca aplicação para o diagnóstico das enfermidades hepáticas e/ou distúrbios metabólicos que acometem os bovinos. Apesar de concordar com Kweon et al. ${ }^{28}$ que a determinação dos valores de referência de colesterol de vacas em lactação apresenta dificuldades em função de inúmeros fatores, ao analisar a literatura compulsada concluiuse que os principais fatores de variabilidades podem ser individualizados, sendo que, afora a influência dos fatores etários, devem ser destacados a influência do periparto e influência da produção de leite.

Com relação à influência dos fatores etários observou-se, ainda, que os teores de triglicérides dos animais com idade maior do que 48 meses foram menores do que nos animais mais jovens sendo considerado fundamental no estabelecimento dos valores de referência que os mesmos fossem apresentados de acordo com duas faixas etárias. Respeitando-se essas faixas etárias e considerando-se os intervalos de confiança obtidos para esta variável, recomenda-se a adoção dos valores de referência para os teores de triglicérides - entre 16,3 e 36,4 mg/ dL para animais com até 48 meses de idade; entre 14,9 e $24,0 \mathrm{mg} / \mathrm{dL}$ para animais com mais de 48 meses de idade.

Os teores de glicose diminuíram gradualmente com o evoluir da idade. Pelos resultados obtidos nesta pesquisa evidenciouse a significativa influência dos fatores etários nos valores de glicose.

$\mathrm{Na}$ tabela 3 estão apresentados os intervalos de confiança dos grupos estudados para avaliação da influência dos fatores sexuais e os resultados que evidenciam que o lipidograma sofreu influência pois os teores de colesterol e $\beta$ $\mathrm{HBO}$ para machos adultos foram menores do que os teores encontrados para fêmeas adultas enquanto os teores de glicose de machos adultos foram maiores que os teores encontrados para fêmeas adultas.

Para machos adultos, com mais de 24 meses de idade, recomenda-se a adoção dos valores de referência para os teores de colesterol - entre 73,9 e 90,2 mg/dL. Ao compararem-se os resultados obtidos na presente pesquisa com aqueles referidos por Sinha et al. ${ }^{26}$ para machos verificou-se que há grande discordância entre os resultados, pois Sinha et al. ${ }^{26}$ encontrou valores maiores do que $150 \mathrm{mg} / \mathrm{dL}$. Com relação à pesquisa de Bellmann et al. ${ }^{31}$, a comparação não pode ser efetuada, pois os bezerros utilizados tinham nove meses de idade.

A análise dos resultados obtidos evidenciou que os valores dos AGNE sofreram influência dos fatores etários e sexuais e, considerando-se os intervalos de confiança obtidos, recomenda-se a adoção dos valores de referência dos teores de AGNE - entre 91,3 e 294,0 $\mu \mathrm{M} / \mathrm{L}$ independente da faixa etária.

O lipidograma, conforme a tabela 4, sofreu influência da gestação, pois os teores de AGNE foram maiores no terço final de gestação enquanto os teores de $\beta-\mathrm{HBO}$ foram maiores no terço inicial de gestação. Durante o puerpério observou-se a influência no lipidograma, pois nos 30 dias após a parição verificou-se que os teores de AGNE e $\beta-\mathrm{HBO}$ foram maiores enquanto que os teores de triglicérides foram menores nos animais paridos em relação àqueles que estavam em gestação. Na tabela 4 são apresentados, ainda, os intervalos de confiança encontrados nos grupos estudados para avaliação da influência da gestação no lipidograma.

Ao fazer a comparação dos resultados do colesterol obtidos com aqueles referidos como padrões na literatura ${ }^{1,5,8,10,20,22,23,25,27,28,29,30}$ observou-se que existe grande variação dos valores apresentados pelos autores, sendo que entre os fatores causadores desta variabilidade 
Tabela 3 - Valores de referência do lipidograma (média \pm desvio-padrão e intervalo de confiança) de bovinos da raça Holandesa, criados no Estado de São Paulo, distribuídos segundo a influência dos fatores sexuais. São Paulo, 2006

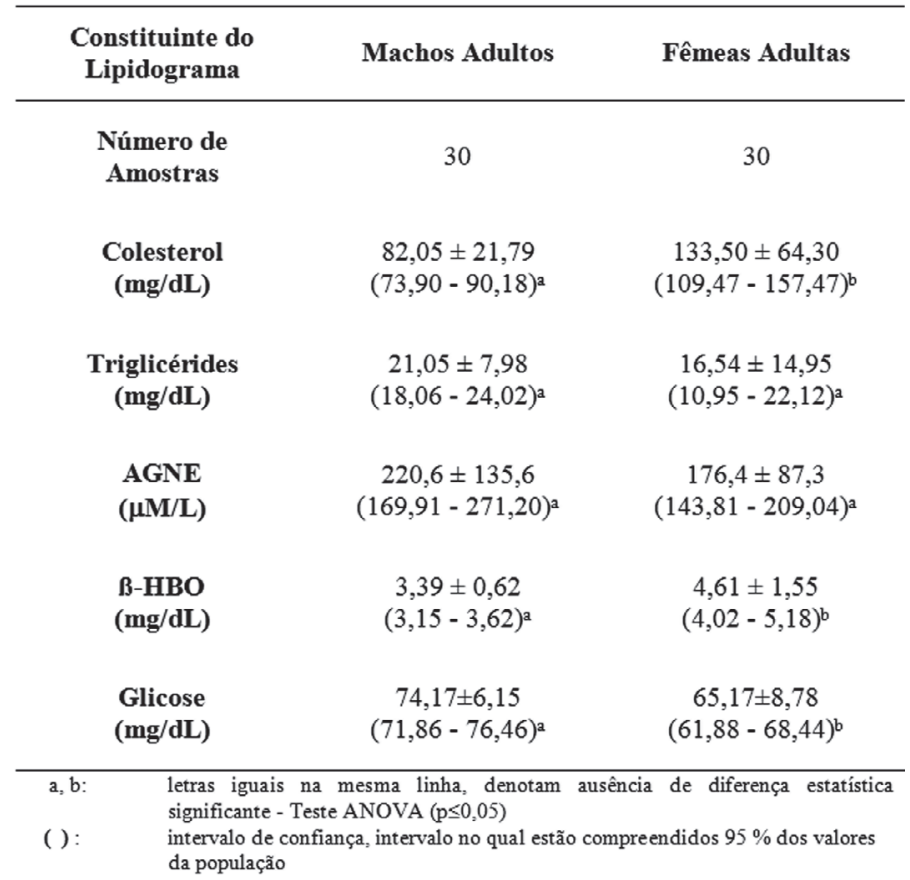

Tabela 4 - Valores de referência do lipidograma (média \pm desvio-padrão e intervalo de confiança) de bovinos da raça Holandesa, criados no Estado de São Paulo, distribuídos segundo a influência da gestação. São Paulo, 2006

\begin{tabular}{|c|c|c|c|c|c|c|}
\hline \multirow{2}{*}{$\begin{array}{c}\text { Grupos } \\
\text { Experimentais }\end{array}$} & \multirow{2}{*}{$\begin{array}{c}\text { Número } \\
\text { de } \\
\text { Amostras }\end{array}$} & \multicolumn{5}{|c|}{ Constituinte do Lipidograma } \\
\hline & & $\begin{array}{c}\text { Colesterol } \\
(\mathbf{m g} / \mathbf{d L})\end{array}$ & $\begin{array}{l}\text { Triglicérides } \\
\text { (mg/dL) }\end{array}$ & $\begin{array}{l}\text { AGNE } \\
(\mu \mathbf{M} / \mathbf{L})\end{array}$ & $\begin{array}{l}\text { B-HBO } \\
(\mathrm{mg} / \mathrm{dL})\end{array}$ & $\begin{array}{l}\text { Glicose } \\
(\mathrm{mg} / \mathrm{dL})\end{array}$ \\
\hline Vazias & 16 & $\begin{array}{c}92,42 \pm 19,73 \\
(81,90-102,93)^{2}\end{array}$ & $\begin{array}{c}29,60 \pm 16,32 \\
(20,08-34,12)^{a}\end{array}$ & $\begin{array}{c}190,14 \pm 130,87 \\
(120,39-259,87)^{a}\end{array}$ & $\begin{array}{c}3,00 \pm 0,85 \\
(2,54-3,45)^{a}\end{array}$ & $\begin{array}{c}72,25 \pm 8,63 \\
(67,64-76,85)^{a}\end{array}$ \\
\hline $\begin{array}{l}\leq 3 \text { meses de } \\
\text { gestação }\end{array}$ & 18 & $\begin{array}{c}111,74 \pm 37,34 \\
(91,83-123,96)^{a}\end{array}$ & $\begin{array}{c}38,47 \pm 21,65 \\
(23,80-44,25)^{a}\end{array}$ & $\begin{array}{c}196,57 \pm 131,89 \\
(113,29-223,63)^{a}\end{array}$ & $\begin{array}{c}4,56 \pm 1,83 \\
(3,64-5,47)^{b}\end{array}$ & $\begin{array}{c}66,38 \pm 4,59 \\
(64,10-68,17)^{b}\end{array}$ \\
\hline $\begin{array}{l}3 \nmid 6 \text { meses de } \\
\text { gestação }\end{array}$ & 15 & $\begin{array}{c}129,98 \pm 63,12 \\
(94,63-148,41)^{2}\end{array}$ & $\begin{array}{c}31,34 \pm 14,08 \\
(18,91-38,47)^{2}\end{array}$ & $\begin{array}{c}220,39 \pm 83,46 \\
(174,17-266,60)^{a}\end{array}$ & $\begin{array}{c}3,50 \pm 0,96 \\
(2,96-4,02)^{2}\end{array}$ & $\begin{array}{c}66,00 \pm 8,41 \\
(61,34-70,65)^{b}\end{array}$ \\
\hline $\begin{array}{l}6 \nmid 9 \text { meses de } \\
\text { gestação }\end{array}$ & 15 & $\begin{array}{c}128,74 \pm 63,26 \\
(94,63-146,93)^{a}\end{array}$ & $\begin{array}{c}29,44 \pm 9,55 \\
(19,68-36,23)^{a}\end{array}$ & $\begin{array}{c}271,26 \pm 144,99 \\
(190,96-351,54)^{b}\end{array}$ & $\begin{array}{c}3,36 \pm 1,04 \\
(2,77-3,93)^{a}\end{array}$ & $\begin{array}{c}63,26 \pm 5,92 \\
(59,98-66,54)^{b}\end{array}$ \\
\hline $\begin{array}{c}\leq \mathbf{3 0} \text { dias de } \\
\text { puerpério }\end{array}$ & 15 & $\begin{array}{c}104,55 \pm 39,39 \\
(94,06-127,03)^{a}\end{array}$ & $\begin{array}{c}12,35 \pm 5,71 \\
(6,55-15,79)^{b}\end{array}$ & $\begin{array}{c}394,19 \pm 236,84 \\
(263,03-525,34)^{b}\end{array}$ & $\begin{array}{c}4,76 \pm 2,12 \\
(3,58-5,93)^{b}\end{array}$ & $\begin{array}{c}66,73 \pm 5,95 \\
(63,43-70,03)^{c}\end{array}$ \\
\hline
\end{tabular}

a,b, $\mathbf{c}$ : letras iguais na mesma coluna denotam ausência de diferença estatística significante $(\mathrm{p} \leq 0,05)$ - Método de Calinski e Corsten (AGNE, $\boldsymbol{\beta}$ - HBO e glicose) e Método de Bonferroni (colesterol e triglicérides).

() : intervalo de confiança, intervalo no qual estão compreendidos $95 \%$ dos valores da população

poderiam ser relacionados a raça, o sexo, o colesterol fez que alguns autores sistema de criação - dieta e alimentação - e, questionassem o uso desse parâmetro para principalmente, a idade, o parto e o diagnóstico de distúrbios do metabolismo puerpério. Esta variabilidade nos teores de lipídico nos bovinos. ${ }^{28}$ 
Recomenda-se a não utilização dos valores de referência apresentados para vacas no último mês de gestação e nos primeiros 45 dias de lactação. Recomenda-se pare este período valores de referência específicos para animais no periparto, pois as pesquisas de Kappel et al. ${ }^{20}$, demonstraram que o colesterol está diminuído durante os primeiros 40 dias pós-parto e concluem que, para a utilização do colesterol como um índice de status metabólico para predição de eficiência reprodutiva, deve-se levar em consideração os dias pré ou pós-parto. Souza $^{2}$, recomendou, para que o colesterol seja utilizado como um indicativo de distúrbios de fertilidade relacionados a esteatose hepática e/ou distúrbios do metabolismo lipídico, ser necessário uma acentuada diminuição dos teores, sendo proposto para vacas em fase pós-puerperal - mais de 45 dias de paridas - teor de colesterol menor do que $100 \mathrm{mg} / \mathrm{dL}$ como sendo significativo da existência de um distúrbio do metabolismo lipídico.

Baseado nos resultados obtidos na presente pesquisa e referidos na literatura brasileira $^{1,2}$, recomenda-se para o periparto e puerpério recente a adoção dos valores de referência para o colesterol: entre 32,2 e 103,3 mg/dL.

Por fim, Kweon et al..$^{28}$, determinaram que existe correlação positiva entre a produção de leite e os níveis de colesterol, indicando que o intervalo de valores normais em vacas em lactação varia de acordo com sua produção diária de leite.

Ao compararem-se os valores de referência obtidos com os referidos na literatura compulsada verificou-se que estão em concordância com Costa ${ }^{1}$, Souza ${ }^{2}$ e Rennó Neto ${ }^{10}$ e estão em discordância com Kaneko et al..$^{30}$, por serem menores do que os valores encontrados nesta pesquisa assim como estão em discordância com Grimoldi et al. ${ }^{32}$ por serem maiores do que os valores de colesterol encontrados para vacas com mais de 48 meses de idade.

Entretanto devem ser feitas algumas restrições à utilização de alguns dos valores de referência, pois vacas secas possuem níveis de triglicérides maiores que vacas em lactação ${ }^{33}$ enquanto vacas no puerpério ${ }^{1,2}$ ou no início da lactação ${ }^{34}$ apresentam uma significativa diminuição nos teores deste constituinte do lipidograma. Desta forma podemos observar que as principais alterações fisiológicas nos teores de triglicérides estão ligadas diretamente à gestação, parição e lactação. Face ao exposto, não se recomenda a utilização dos valores de referência apresentados para vacas no último mês de gestação e nos primeiros 45 dias de lactação, sendo, para este período, necessário a adoção de valores específicos. Baseado nos resultados e naqueles referidos na literatura brasileira ${ }^{1,2}$, sugere-se para o periparto e puerpério recente a adoção dos valores de referência de triglicérides: entre 6,5 e $15,8 \mathrm{mg} / \mathrm{dL}$.

Ao se confrontar os resultados de AGNE obtidos com aqueles referidos na literatura verificou-se que estão em concordância com Santos ${ }^{6}$, Sucupira ${ }^{9}$, Rennó Neto $^{10}$, Maruta ${ }^{11}$ e Grimoldi et al. ${ }^{32}$ e parcialmente de acordo com $\operatorname{Costa}^{1} \mathrm{e}$ Souza $^{2}$ desde que não sejam considerados para esta comparação os valores obtidos no final da gestação e no puerpério recente. Relativo a influência da gestação e do puerpério observou-se, assim como os referidos na literatura, a significativa influência do periparto, sendo constatado a existência de uma absoluta concordância entre os autores de que no puerpério os teores de AGNE são maiores do que os observados nos dois primeiros terços da gestação ou na fase pós-puerperal. 1,2,6,10,32,35

Com relação aos valores de referência para AGNE apresentados, recomenda-se a não utilização dos mesmos para vacas no último mês de gestação e nos primeiros 45 dias de lactação e a adoção de valores de referência específicos para animais nesta fase. Baseado nos resultados obtidos e naqueles da literatura brasileira ${ }^{1,2}$ recomenda-se os valores de referência do AGNE durante o periparto e puerpério recente: entre 263,0 e 525,3 $\mu \mathrm{M} / \mathrm{L}$.

Com relação aos valores do $\beta$-HBO foi evidenciado a influência dos fatores 
etários e sexuais, pois nos três primeiros meses de vida e nos machos adultos foram encontrados valores menores do que, respectivamente, em animais mais idosos e em fêmeas adultas. Assim, considerando-se os intervalos de confiança obtidos, recomenda-se a adoção dos valores de referência de $\mathrm{B}-\mathrm{HBO}$ - entre 1,1 e 2,1 mg/ dL para bezerros com até 3 meses de idade; entre 3,37 e $6,2 \mathrm{mg} / \mathrm{dL}$ para animais com mais de 3 meses de idade. Em relação aos machos adultos, com mais de 24 meses de idade, recomenda-se a adoção de valores de referência diferenciados - entre 3,1 e $3,6 \mathrm{mg} / \mathrm{dL}$.

Ao se confrontar os resultados obtidos com aqueles referidos na literatura verificou-se concordância com os referidos por Souza ${ }^{2}$, Santos ${ }^{6}$ e Sucupira ${ }^{9}$ e em disconcordância com os resultados relatados por Maruta ${ }^{11}$ e Bellmann et al. ${ }^{31}$ que encontraram valores médios de $\mathrm{B}-\mathrm{HBO}$ maiores para machos.

Apesar dos resultados obtidos, assim como aqueles referidos na literatura, evidenciarem que os teores de $\mathrm{B}-\mathrm{HBO}$ sofreram influência do puerpério ${ }^{6,36}$, verificou-se que pela magnitude das variações observadas no puerpério para os teores séricos de $B-\mathrm{HBO}$ não existe a necessidade da adoção de valores de referência específicos para o período, desta forma recomenda-se que neste período seja utilizado o intervalo de valores apresentado para animais com mais de 3 meses de idade, ou seja, entre 3,37 e 6,2 mg/dL.

A análise dos resultados evidenciou a influência dos fatores etários na glicemia, sendo considerado fundamental no estabelecimento dos valores de referência que os mesmos fossem apresentados de acordo com a influência dos fatores etários: nos primeiros três meses de vida verificouse diminuição dos níveis de glicose; entre 3 e 24 meses de idade os teores de glicose permaneceram estabilizados; nos animais com mais de 24 meses de vida, observouse que os teores de glicose foram menores do que os verificados nos primeiros 24 meses de vida.
Respeitando-se as faixas etárias e considerando-se os intervalos de confiança obtidos, recomenda-se os valores de referência para os teores de glicose: entre 75,1 e $88,3 \mathrm{mg} / \mathrm{dL}$ para bezerros lactentes com até 3 meses de idade; entre 64,0 e 76,1 mg/ $\mathrm{dL}$ para animais entre 3 e 24 meses de idade; entre 60,6 e $67,2 \mathrm{mg} / \mathrm{dL}$ para vacas adultas com mais de 24 meses. Em relação aos valores de referência para glicose estabelecidos em pesquisas realizadas no Brasil foi observado que os valores de referência obtidos nesta pesquisa estão em concordância com Souza ${ }^{37}$ e estão em discordância com os valores de Souza ${ }^{2}$, Santos ${ }^{6}$ e Rennó Neto ${ }^{10}$ por serem menores do que os valores desta pesquisa e daqueles apresentados por Maruta ${ }^{11}$ por serem maiores do que os valores desta pesquisa. Estas variações nos valores de referência dos teores de glicose são um reflexo da influência de diversos fatores que não foram objeto de estudo nesta pesquisa como a raça ${ }^{3}$, os níveis de energia na dieta ${ }^{9,11} \mathrm{e}$ a produção de leite ${ }^{20}$.

Os fatores climáticos como a umidade e a temperatura relacionadas às estações do ano, também, podem influenciar os valores dos teores de glicose, pois em meses mais quentes há aumento da freqüência respiratória causando rápida utilização da glicose sangüínea pelos músculos respiratórios e assim resultando em uma queda na glicemia sob stress do calor $^{38}$. Ao compararem-se os valores de referência desta pesquisa observou-se que os mesmos estão em discordância com Shaffer et al. ${ }^{38}$ pois os resultados apresentados como referência em pesquisas realizadas em países de climas temperados ${ }^{21,24,38}$, nos quais as temperaturas médias anuais são menores do que as do Estado de São Paulo, foram menores do que os valores obtidos como referência em nosso Estado.

Em relação aos fatores sexuais recomendou-se para machos adultos, com mais de 24 meses de idade, a adoção de valores de referência diferenciados para os teores de glicose entre 71,9 e 76,5 mg/dL.

Os resultados obtidos assim como 
aqueles referidos na literatura evidenciaram que os teores de glicose não sofreram influência da gestação ou do puerpério ${ }^{39,40}$, desta forma não existe a necessidade da adoção de valores de referência específicos, sendo recomendado para este período o intervalo de valores apresentado para animais com mais de 24 meses de idade, ou seja, entre 60,6 e 67,2 mg/dL.

\section{Conclusões}

Diante dos resultados obtidos e considerando-se os fatores de variabilidade, recomenda-se, baseado nos intervalos de confiança, a adoção dos valores de referência para o lipidograma de bovinos da raça Holandesa, criados no Estado de São Paulo: -teores de colesterol - entre 86,5 e $120,8 \mathrm{mg} / \mathrm{dL}$ para bezerros lactentes com até 3 meses de idade; entre 46,3 e 79,7 mg/ $\mathrm{dL}$ para bezerros desmamados com 3 a 12 meses de idade; entre 86,4 e 105,0 mg/dL para novilhas com 12 a 24 meses de idade; entre 116,0 e $147,9 \mathrm{mg} / \mathrm{dL}$ para vacas adultas com mais de 24 meses de idade;

-teores de triglicérides - entre 16,3 e $34,8 \mathrm{mg} / \mathrm{dL}$ para animais com até 48 meses de idade; entre 14,9 e $24,0 \mathrm{mg} / \mathrm{dL}$ para animais com mais de 48 meses de idade; -teores de AGNE - entre 91,3 e 294,0 $\mathrm{mM} / \mathrm{L}$ independente da faixa etária; -teores de $\mathrm{B}-\mathrm{HBO}$ - entre 1,1 e 2,1 $\mathrm{mg} / \mathrm{dL}$ para bezerros com até 3 meses de idade; entre 3,37 e 6,2 mg/dL para animais com mais de 3 meses de idade;

-teores de glicose - entre 75,1 e 88,3 $\mathrm{mg} / \mathrm{dL}$ para bezerros lactentes com até 3 meses de idade; entre 64,0 e 76,1 mg/dL para animais jovens entre 3 e 24 meses de idade; entre 60,6 e 67,2 mg/dL para vacas adultas com mais de 24 meses;

-para machos adultos, com mais de 24 meses de idade, recomenda-se a adoção de valores de referência diferenciados para: teores de colesterol - entre 73,9 e 90,2 mg/ $\mathrm{dL}$; teores de $3-\mathrm{HBO}$ - entre 3,1 e 3,6 mg/ $\mathrm{dL}$ e teores de glicose - entre 71,9 e 76,5 $\mathrm{mg} / \mathrm{dL}$;

-os valores de referência apresentados não devem ser utilizados para vacas que estejam no último mês de gestação e nos primeiros 45 dias de lactação, sendo recomendado a adoção de valores de referência específicos para animais na fase de periparto.

Pesquisa realizada com auxílio pesquisa da FAPESP, processo n ${ }^{\circ}$ 04/06773-2.

\section{Reference values of the lipid profile of Holstein cattle bred in state of São Paulo}

\footnotetext{
Abstract

In order to establish the reference values for the lipid profile of Holstein cattle, bred in the state of São Paulo we analyzed samples of blood serum and plasma of 413 healthy animals. We suggest, based on the confidence interval, the use of the following reference values: cholesterol - between 86.5 and $120.8 \mathrm{mg} / \mathrm{dL}$ for calves up to 3 months old; between 46.3 and $79.7 \mathrm{mg} / \mathrm{dL}$ for calves between 3 and 12 months; between 86.4 and $105.0 \mathrm{mg} / \mathrm{dL}$ for heifers between 12 and 24 months; between 116.0 and $147.9 \mathrm{mg} / \mathrm{dL}$ for cows older than 24 months; triglycerides - between 16.3 and $34.8 \mathrm{mg} / \mathrm{dL}$ for animals up to 48 months; between 14.9 and $24.0 \mathrm{mg} / \mathrm{dL}$ for animals older than 48 months; NEFA - between 91.3 and $294.0 \mu \mathrm{M} / \mathrm{L}$ regardless of the age; $\mathrm{B}-\mathrm{HBO}$ - between 1.1 and $2.1 \mathrm{mg} / \mathrm{dL}$ for calves up to 3 months old; between 3.37 and $6.2 \mathrm{mg} / \mathrm{dL}$ for animals older than 3 months; glucose - between 75.1 and $88.3 \mathrm{mg} / \mathrm{dL}$ for calves up to 3 months
}

Key words: Lipid profile. Reference values. Bovine. Holstein Cattle. 
old; between 64.0 and $76.1 \mathrm{mg} / \mathrm{dL}$ for animals between 3 and 24 months; between 60.6 and $67.2 \mathrm{mg} / \mathrm{dL}$ for cows older than 24 months. For adult males, older than 24 months, we suggest different reference values for the following constituents: cholesterol - between 73.9 and $90.2 \mathrm{mg} / \mathrm{dL}$; B-HBO - between 3.1 and $3.6 \mathrm{mg} / \mathrm{dL}$ and glucose between 71.9 and $76.5 \mathrm{mg} / \mathrm{dL}$. The reference values that were previously presented should not be used for cows in the last month of gestation and in the first 45 days of lactation. In this case, the reference values should be specific for animals around parturition.

\section{Referências}

1 COSTA, S. G. Perfil lipídico de vacas Holandesas, variedade HPB, em diferentes fases da gestação. 1991. 57 f. Dissertação (Mestrado) - Faculdade de Medicina Veterinária e Zootecnia, Universidade de São Paulo, São Paulo, 1991.

2 SOUZA, R. M. Avaliação da função hepática e do lipidograma no período puerperal e pós-puerperal e suas inter-relações com os distúrbios reprodutivos de fêmeas bovinas da raça Holandesa, criadas no Estado de São Paulo. 2005. 192 f. Dissertação (Mestrado) Faculdade de Medicina Veterinária e Zootecnia, Universidade de São Paulo, São Paulo, 2005.

3 VOGEL, J.; RUSSO, E.; SZECHY, A. M. Contribuição a bioquímica do sangue de zebus (Bos indicus) das raças Nelore e Guzerá. Revista Militar de Remonta e Veterinária, v. 17, n. 1-4, p. 47-55, 1957.

$4 \mathrm{MANCIO}, \mathrm{A}$. B. Plano nutricional, gonadotrofina coriônica humana (hCG) e amamentação na função reprodutiva e metabólica de fêmeas bovinas. 1994. 158 f. Tese (Doutorado) - Universidade Federal de Viçosa, Viçosa, 1994.

5 OLIVEIRA, F. N. Concentrações sangüíneas de progesterona e metabólitos lipídicos em novilhas tratadas com Norgestomet e valerato de estradiol (Syncro-Mate B) e submetidas à dieta hiperlipidêmica. 1995. 75 f. Dissertação (Mestrado) - Universidade Federal de Viçosa, Viçosa, 1995.

6 SANTOS, M. V. Correlação entre ácido ascórbico plasmático, contagem de células somáticas no leite e o perfil metabólico de vacas secas e em lactação. 1998. 97 f. Dissertação (Mestrado em Nutrição Animal) Faculdade de Medicina Veterinária e Zootecnia, Universidade de São Paulo, São Paulo, 1998.

$7 \mathrm{MANCIO}, \mathrm{A}$. B. et al. Fontes lipídicas dietéticas associadas ou não à gonadotrofina coriônica humana (hCG) na função reprodutiva e no metabolismo de lípides de novilha. Arquivo Brasileiro de Medicina Veterinária e Zootecnia, v. 51, n. 2, p. 163-170, 1999.

8 BORGES, A. M. et al. Concentração plasmática de colesterol total e lipoproteína de alta densidade em novilhas mestiças doadoras de embriões tratadas com somatotropina bovina recombinante. Arquivo Brasileiro de Medicina Veterinária e Zootecnia, v. 53, n. 5, p. 605-610, 2001.
9 SUCUPIRA, M. C. A. Estudo comparativo de exames clínico-laboratoriais no diagnóstico de carência energética prolongada em garrotes. 2003. $173 \mathrm{f}$. Tese (Doutorado) - Faculdade de Medicina Veterinária e Zootecnia, Universidade de São Paulo, São Paulo, 2003.

10 RENNÓ NETO, B. P. Influência da aplicação da somatotropina recombinante bovina na função hepática, renal e lipidograma de bovinos da raça holandesa em lactação. 2004. 116 f. Dissertação (Mestrado) - Faculdade de Medicina Veterinária e Zootecnia da Universidade de São Paulo, São Paulo, 2004.

11 MARUTA, C. A. Perfil metabólico e ruminal de garrotes submetidos às condições de alimentação normal, jejum e realimentação. 2005. 93 f. Tese (Doutorado em Clínica Veterinária) - Faculdade de Medicina Veterinária e Zootecnia, Universidade de São Paulo, São Paulo, 2005.

12 ELPHICK, M. C. Modified colorimetric ultramicro method for estimating NEFA in serum. Journal of Clinical Pathology, v. 21, n. 5, p. 567-570, 1968.

13 ALLAIN, C. C. et al. Enzymatic determination of total serum cholesterol. Clinical Chemistry, v. 20, n. 4, p. 470-475, 1974.

14 FOSSATI, P.; PRENCIPE, L. Serum triglycerides determined colorimetrically with an enzyme that produces hydrogen peroxide. Clinical Chemistry, v. 28, n. 10, p. 2077-2080, 1982

15 WILLIAMSON, D. H. et al. Enzymatic determination of $\mathrm{D}(-)$ B-hydroxybutyric acid and acetoacetic acid in blood. Biochemical Journal, v. 82, p. 90, 1962.

16 BARHAM, D.; TRINDER, P. An Improved colour reagent for the determination of blood glucose by the oxidase system. Analyst, v. 97, p. 142-145, 1972.

17 BROWN, M. B.; FORSYTHE, A. B. The ANOVA and multiplpe comparisons for data with heterogenous variances. Biometrics, v. 30, p. 719-724, 1974.

18 CALINSKI, T.; CORSTEN, L. C. A. Clustering means in ANOVA by simultaneous testing. Biometrics, v. 41, p. 39-48, 1985.

19 NETER, J. et al. Applied linear statistical models. Boston: McGrow Hill, 1996. 1408 p.

20 KAPPEL, L. C. et al. Relationship between fertility and blood glucose and cholesterol concentration in 
Holstein cows. American Journal of Veterinary Research, v. 45, n. 12, p. 2607-2612, 1984.

21 ROUSSEL, J. D. et al. Metabolic profile testing for Jersey cows in Louisiana: reference values. American Journal of Veterinary Research, v. 43, n. 6, p. 10751077, 1982.

22 TALAVERA, F. et al. Relationships among dietary lipid intake, serum cholesterol and ovarian function in Holstein heifers. Journal of Animal Science, v. 60, p. 1045-1051, 1985.

23 ARAVE, C. W. et al. Genetic and environmental effects on serum cholesterol of dairy cattle of various ages. Journal of Dairy Science, v. 58, p. 423-427, 1975.

24 ROUSSEL, J. D. et al. Metabolic profile testing fot holstein cattle in Louisiana: reference values. American Journal of Veterinary Research, v. 43, n. 9, p. 16581660,1982

25 GRUMMER, R. R.; CARROL, D. J. A review of lipoprotein cholesterol metabolism: importance to ovarian function. Journal of Animal Science, v. 66, p. 3160-3173, 1988.

26 SINHA, R. K. et al. Effect of breed, age, sex and season on total serum cholesterol level in cattle. Indian Veterinary Journal, v. 58, n. 7, p. 529-533, 1981.

27 WILLIAMS, G. L. Modulation of luteal activity in postpartum beef cows through changes in dietary lipid. Journal of Animal Science, v. 67, p. 785-793, 1989.

28 KWEON, O. K. et al. Factors affecting serum total cholesterol level of lactating Holstein cows. Japanese Journal Veterinary Science, v. 48, n. 3, p. 481-486, 1986.

29 SMITH, B. P. Tratado de medicina interna de grandes animais. São Paulo: Manole, 1992. 1661 p.

30 KANEKO, J. J. et al. Clinical biochemistry of domestic animals. California: Academic Press, 1997. $932 \mathrm{p}$.
31 BELLMANN, O. et al. Beef versus dairy cattle: a comparison of metabolically relevant hormones, enzymes, and metabolites. Livestock Production Science, v. 89, n. 1, p. 41-54, 2004.

32 GRIMOLDI, R. J. et al. Perfil lipidico en bovinos de leche. Veterinaria Argentina, v. 22, p. 162-164, 1986.

33 PEHRSON, B. Studies of the blood lipid pattern in healthy dairy cows. Acta Vet. Scand., v. 12, n. 2, p. 230-242, 1971

34 EMERY, R. S. et al. Metabolism of long chain fatty acids by ruminant liver. Journal of Nutrition, v. 122, n. 35, p. 832-837, 1992.

35 CHRISTIE, W. W. Effects of diet on lipid composition In: CHRISTIE, W.W. Lipid metabolism in ruminants animals. Oxford: Pergamon Press, 1981. p. 452.

36 PÖSÖ, A. R.; LINDBERG, L. A. Plasma protein synthesis and serum amino acids in dry and lactating dairy cows. Journal Veterinary Medicine, v. 41, p. 7275, 1994.

37 SOUZA, P. M. Perfil bioquímico sérico de bovinos das raças Gir, Holandesa e Girolanda, criados no Estado de São Paulo - influência de fatores de variabilidade etários e sexuais. 1997. 168 f. Tese (Doutorado) Faculdade de Medicina Veterinária e Zootecnia, Universidade de São Paulo, São Paulo, 1997.

38 SHAFFER, L. et al. Effects of age, temperature-season, and breed on blood characteristics of dairy cattle. Journal of Dairy Science, v. 64, n. 1, p. 62-70, 1981.

39 GRIGSBY, J. S. et al. Serum insulin, glucose, and free fat acids in the cow and fetus during gestation. Proceedings of the Society for Experimental Biology and Medicine, v. 147, p. 830-834, 1974.

40 MARQUES JUNIOR, A. P.; CASTILLO CASTILLO, O. A. Glicose e triglicérides plasmáticos de vacas holandesas próximo ao parto e no puerpério. Arquivo Brasileiro de Medicina Veterinária e Zootecnia, v. 48, n. 3, p. 309-315, 1996. 